\title{
Isolation and Characterization of Antimicrobial Compound from Stem Bark of Traditional-Medicinal Plant Sonneratia apetala: Evaluation of their antimicrobial, Cytotoxic and Antioxidant Properties
}

\author{
Md. Arifur Rahman ${ }^{1}$, Ahmed Abu Rus'd ${ }^{1 *}$, Md. Enamul Haque ${ }^{2}$ \\ ${ }^{I}$ Department of Microbiology, Jagannath University, Dhaka 1100, Bangladesh, ${ }^{2}$ Department of Biochemistry and Molecular Biology, University of Dhaka, \\ Bangladesh.
}

\begin{abstract}
Sonneratia apetala (S. apetala) (Lythraceae) has been investigated for the isolation and characterization of antimicrobial compounds and evaluation of their biological activities. The chloroform extract of the stem bark and different partitionate of the chloroform extracts i.e. Petroleum ether soluble fraction (PESF), Ethyl acetate soluble fraction(EASF), Methanol soluble fraction(MSF) and aqueous soluble fractions (ASF) were subjected to different chromatographic techniques to isolate secondary metabolites. Successive chromatographic separation and purification yielded a total of two compounds identified and characterized as Taraxerone(1) and 5,8-dihydroxy6-methoxy-4,9-dioxo-1,3,4,9-tetrahydronaphthol[2,3-c]furan-1-yl acetate (2) by extensive proton NMR spectrum $\left({ }^{1} \mathrm{H}-\mathrm{NMRspectrum}\right)$ analysis. The different partitionate like PESF, EASF, MESF and ASF were subjected to screen their antimicrobial properties against some selected Gram positive and Gram negative bacteria and fungi, brine shrimp lethality and antioxidant activities. The maximum zone of inhibition of chloroform extract was found against Pseudomonas sp. (16mm). All fractions showed more activity against Gram negative bacteria then Gram positive bacteria. In the brine shrimp lethality bioassay, among all extracts, the petroleum ether and ethyl acetate soluble fraction showed significant lethality having the $\mathrm{LC}_{50}$ value of $7.72 \mu \mathrm{g} / \mathrm{ml}$. The antioxidant activity was evaluated in terms of determination of free radical scavenging activity (DPPH assay). Among all the extracts of $S$. apetala the highest free radical scavenging activity showed by (Methanol soluble fraction) $\mathrm{MESF}$ with $\mathrm{IC}_{50}$ value $18.0 \mu \mathrm{g} / \mathrm{ml}$.
\end{abstract}

Keyword: Sonneratia Apetala; chromatographic technique, Antimicrobial activity; Brine Shrimp lethality; DPPH Assay.

\section{Introduction}

The use of traditional medicine and medicinal plants in most developing countries, as a basis for the maintenance of good health, has been widely observed ${ }^{1}$. Scientists throughout the world are trying to explore the precious assets of medicinal plants to help the suffering humanity ${ }^{2}$. The number of angiosperms and gymnosperms plants on earth is estimated at about 250,000 of which only about $6 \%$ have been tested for biological activity, and a reported $15 \%$ have been evaluated phytochemically ${ }^{3,4}$. Bangladesh is a good source of medicinal plants, of which Lythraceae family includes a considerable numbers of species which have chemical and unique pharmacologically active compounds including antiinflammatory, anti-rheumatic and anti-emetic activities ${ }^{5,6}$.

In Bangladesh, a wide range of cytotoxic compounds has been isolated from various plants of Lythraceae family ${ }^{7}$. S. apetala contain various minerals, vitamins (e.g., ascorbic acid, thiamin, and riboflavin) and a number of biologically active compounds. The bark of $S$. apetala has been investigated for isolation of their secondary metabolites and evaluation of their biological activities with special emphasis on the cytotoxic, antioxidant and antimicrobial activities ${ }^{8,9}$. S. apetala has lots of biological and pharmacological activities, so attempt has been made to study the chemical constituents and biological activities of $S$. apetala extracts.

The main objective of this research is to isolate different active antimicrobial compounds and studies on different bioactivities such as antimicrobial (antibacterial, anti-fungal), cytotoxic, and antioxidant activities of the chloroform extracts from stem bark of $S$. apetala.

\section{Materials and Methods}

The plant materials (stem bark) were collected from Sundarbans mangrove forest of Bangladesh. After drying in sunlight and grinding, the plant material is extracted with chloroform for seven successive days. It was then filtered through filter paper and the filtrate thus obtained was concentrated at $50^{\circ} \mathrm{C}$ with rotator evaporation. Chloroform extract was stored at $4^{\circ} \mathrm{C}$ until use.

The isolation and purification of compounds from plant extracts was performed by chromatography technique. The chloroform extract of $S$. apetala subjected to column chromatography and twenty seven fractions were obtained. The fraction SA-3 and SA5 showed distinct $\mathrm{R}_{\mathrm{f}}$ values and further fractionation of these two fractions were carried out by a preparatory TLC. From TLC study, it was found that, two compounds $1(10 \mathrm{mg})$ and $2(12 \mathrm{mg})$ have been isolated by repeated Preparatory thin layer chromatography (PTLC) and their structures were determined by ${ }^{1} \mathrm{H}-\mathrm{NMR}$ spectroscopy by comparison with published data ${ }^{10}$.

The antimicrobial assay was performed in vitro disc diffusion method ${ }^{11}$. The bacterial (Table 1) and fungal strains (Table 2) used for the experiment were collected as pure cultures from the Institute of Nutrition and Food Sciences (INFS), University of Dhaka, Bangladesh. For experimental purpose sterilized filter paper discs $(6 \mathrm{~mm})$ were used. The discs were impregnated with $50 \mu \mathrm{g} /$ disc of

\footnotetext{
"Corresponding Author:

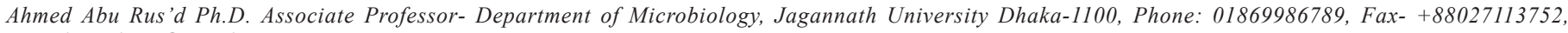

E-mail:roosh031@gmail.com
} 
petroleum ether, ethyl acetate, methanol soluble fractions and pure compounds SA-3 and SA-5 separately in aseptic condition. These discs were left for a few minutes for complete removal of the solvent. Ciprofloxacin $(30 \mu \mathrm{g} / \mathrm{disc})$ was used as a standard antibacterial agent (positive control) and solvent added discs (after evaporation of solvents) as negative control. After incubation, the antibacterial sensitivity of the test samples was determined by measuring the diameter of zones of inhibition (in $\mathrm{mm}$ ).

The antifungal activity of the plant extracts was also performed by disc diffusion method in Potato Dextrose agar (PDA), using the same procedure as antibacterial activity test, but the incubation period of the plates containing different fungus was 48 hours at room temperature. Grisofulvin $(30 \mu \mathrm{g} /$ disc $)$ was used as a standard antifungal agent and solvent added discs (after evaporation of solvents) as negative control.

Cytotoxic activity was performed by Brine Shrimp Lethality test ${ }^{12}$. The lethality test involved the culture of Brine Shrimp, Artemia salina nauplii [Brine shrimp eggs]. The nauplii were grown in test tubes containing sea water. Sea water contain $3.8 \% \mathrm{NaCl}$ solution was made by dissolving $38 \mathrm{~g} \mathrm{NaCl}$ in $1000 \mathrm{ml}$ distilled water and sterilized by $0.45 \mu \mathrm{m}$ filter. The $\mathrm{pH}$ of the brine water thus maintained between $8-9$ using $\mathrm{NaHCO}_{3}$. Constant temperature $\left(37^{\circ} \mathrm{C}\right)$ and sufficient light and aeration were ensured. After 24 hours, the test tubes were observed and the number of survived nauplii in each test tube was counted by probit analysis to determine $\mathrm{LC}_{50}$. Vincristine sulfate was used as the positive control and DMSO as the negative control for the brine shrimp nauplii.

Free radical scavenging activity of the plant extracts against stable DPPH (2, 2 diphenyl -2- picryl hydrazyl) were determined spectrophotometrically ${ }^{13}$. The antioxidant activity of petroleum ether, ethyl acetate and methanol soluble fraction were evaluated by comparing with the standard (ascorbic acid) on the basis of scavenging activity of the stable DPPH free radical. $175 \mathrm{ml}$ solution of DPPH $(20 \mu \mathrm{g} / \mathrm{ml})$ was prepared by dissolving $3.5 \mathrm{mg}$ of DPPH in spectral grade methanol in a $250 \mathrm{ml}$ volumetric flask. Ascorbic acid with same concentration $(20 \mu \mathrm{g} / \mathrm{ml})$ was used as a standard. Different concentrated solutions of extracts were prepared by dissolving dried extracts ranging from $1 \mu \mathrm{g} / \mathrm{ml}$ to $500 \mu \mathrm{g} / \mathrm{ml}$ in spectral grade methanol solvent. DPPH (freshly prepared) was added to each solution and kept in dark for $30 \mathrm{~min}$ to complete the reaction. After 30 minutes, absorbance of each test tube was taken by a spectrophotometer at $517 \mathrm{~nm}$ and inhibition of free radical DPPH oxidant was calculated in percentage (Inhibition \%) as follows:

(Inhibition $\left.\%=1-\mathrm{A}_{\text {sample }} / \mathrm{A}_{\text {blank }}\right) \times 100$

The $\mathrm{IC}_{50}$ was determined from $\%$ inhibition $\mathrm{Vs}$ concentrated graph (Figure- 6)

\section{Results and Discussion}

The chloroform extract of $S$. apetala was subjected to column chromatography then twenty seven fractions were obtained from TLC study. From these fractions only two fractions named as SA3 and SA5 showed distinct Rf values than these two fractions were screened to assess the type of compounds present. From fractions SA-3 and SA-5, two known compounds have been isolated. These compounds are taraxerone (compound-1) and 5,8dihydroxy-6-methoxy-4,9-dioxo-1,3,4,9-tetrahydronaphthol[2,3c] furan-1-yl acetate (compound-2).

The ${ }^{1} \mathrm{H}-\mathrm{NMR}$ spectrum $\left(400 \mathrm{MHz}, \mathrm{CDCl}_{3}\right)$ of SA-3 displayed (Figure-1) 8 three protons singlet at $\delta_{\mathrm{H}} 0.81,0.91,0.92,0.99$,

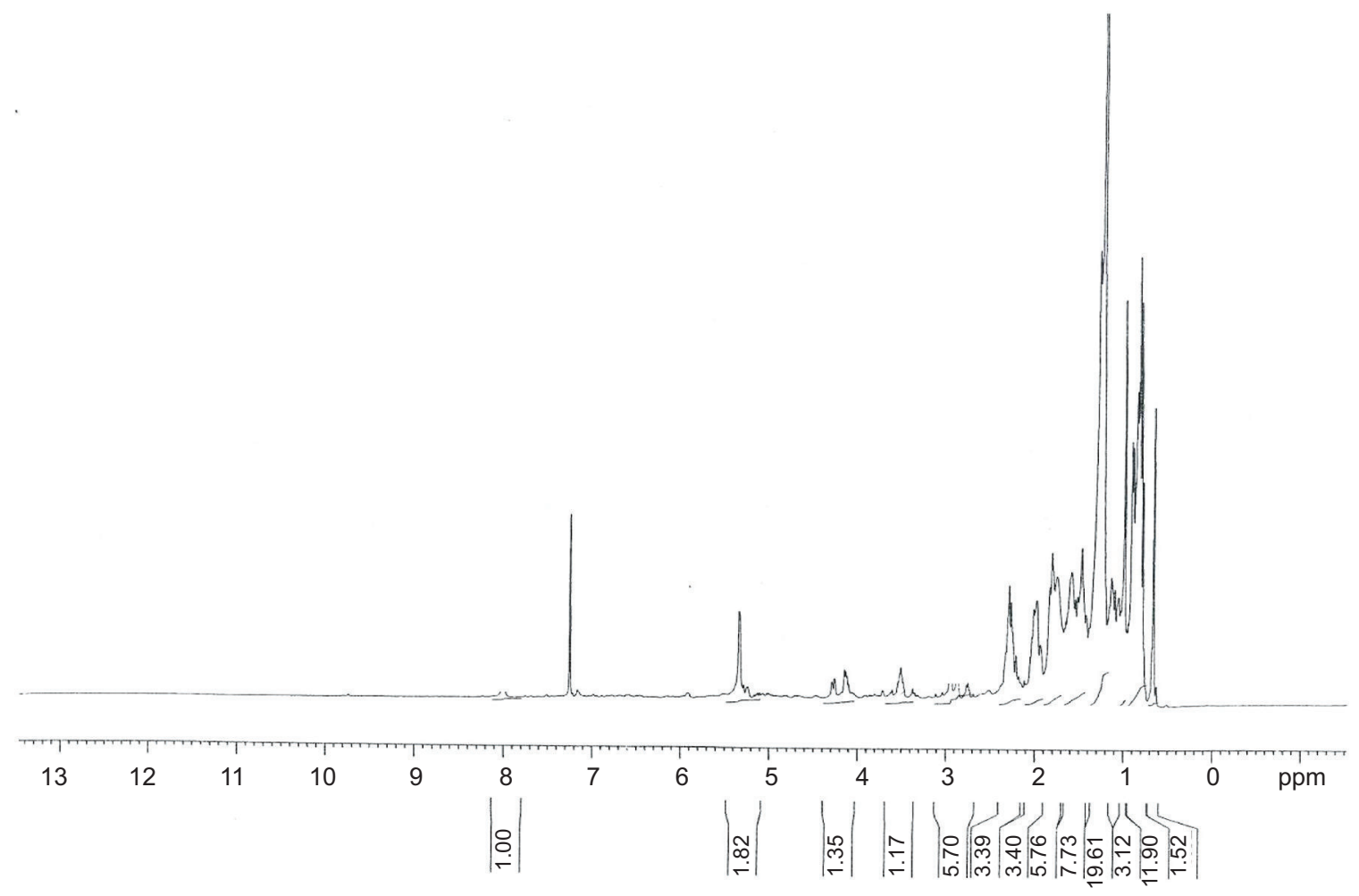

Fig. 1. ${ }^{1} H$-NMR spectrum $(400 M H z, C D C l 3)$ of compound $S A-3$. 
$1.07,1.09,1.10$ and 1.16, for eight methyl groups. The spectrum showed a double doublet at $\delta_{\mathrm{H}} 5.41(\mathrm{~J}=8.2,3.1 \mathrm{~Hz})$ demonstrated an olefin proton at $\mathrm{H}-15$ of a triterpene nucleus. The spectrum showed a double singlet at $\delta_{\mathrm{H}} 3.5$ exhibited a ketone group at $\mathrm{H}$ 3. On this basis and comparing with published data ${ }^{14}$, the isolated compound from the fraction SA-3 was proposed as Taraxerone (Figure-2).

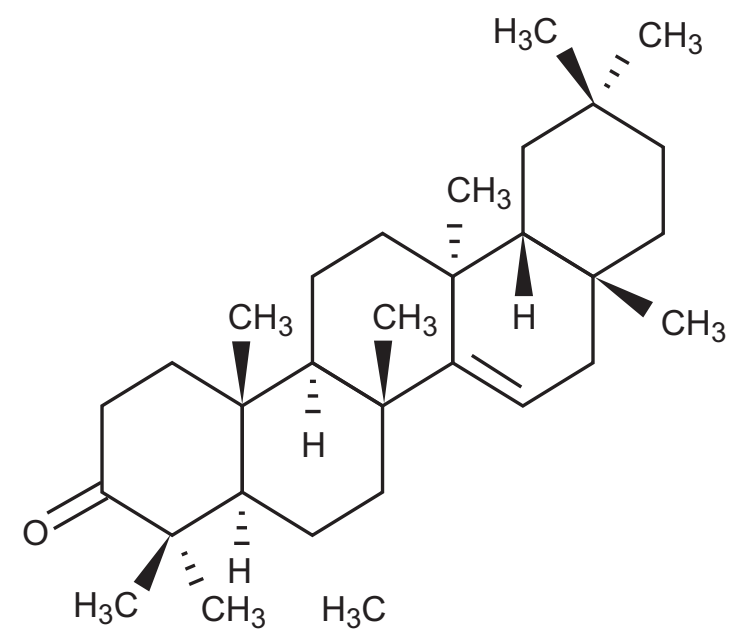

Fig. 2. Taraxerone (1).

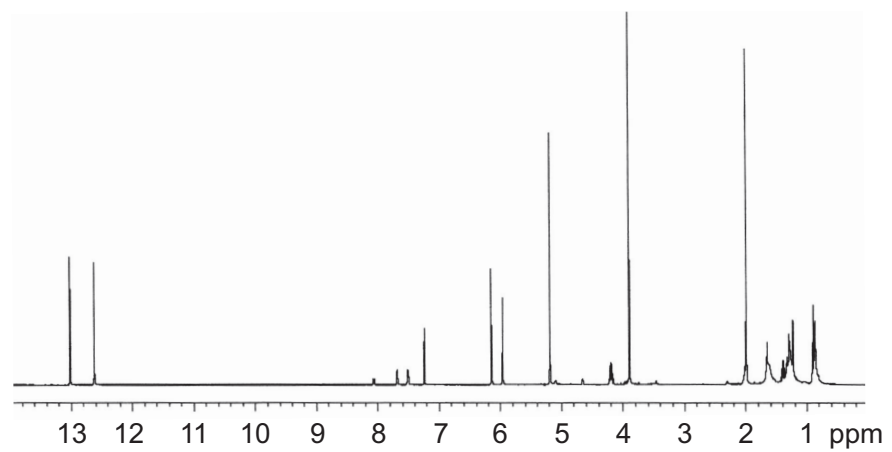

Fig. 3: ${ }^{1} H-N M R$ spectrum of compound SA-5.

The ${ }^{1} \mathrm{H}-\mathrm{NMR}$ spectrum $\left(500 \mathrm{MHz}, \mathrm{CDCl}_{3}\right.$ ) of SA-5 also displayed (Figure-3) seven protons singlet's at $\delta_{\mathrm{H}} 5.961 .96,5.10,13.0,3.88$, 6.16 , and 12.60.The presence of one sharp proton singlet at ' ${ }_{\mathrm{H}}$ $12.60 \mathrm{ppm}$ and $\delta_{\mathrm{H}} 13.0 \mathrm{ppm}$ in ${ }^{1} \mathrm{H}$ NMR spectrum could be attributed to two phenolic chelated hydroxyl groups indicated that each of them might form intramolecular hydrogen bonds with any lone electron pairs of a functional group. The one proton singlet at $\delta_{\mathrm{H}} 5.96 \mathrm{ppm}$ could be attributable to a heteroatom bonded methyl group in SA-5. The presence of the resonance of two-proton singlet at $\delta_{\mathrm{H}}=5.10 \mathrm{ppm}$ indicated the presence of a $\mathrm{CH}_{2}$ group. The three proton singlet at $\delta_{\mathrm{H}} 1.98 \mathrm{ppm}$ in ${ }^{1} \mathrm{H}-\mathrm{NMR}$ spectrum indicated the presence of methyl group. On this basis and comparing with published data ${ }^{14}$, compound in the fraction of SA-5(2) was proposed as 5,8-dihydroxy-6-methoxy-4,9-dioxo1,3,4,9-tetrahydronaphthol[2,3-c]furan-1-ylacetate(Figure-4). This is the first isolation report of the compound from this plant.

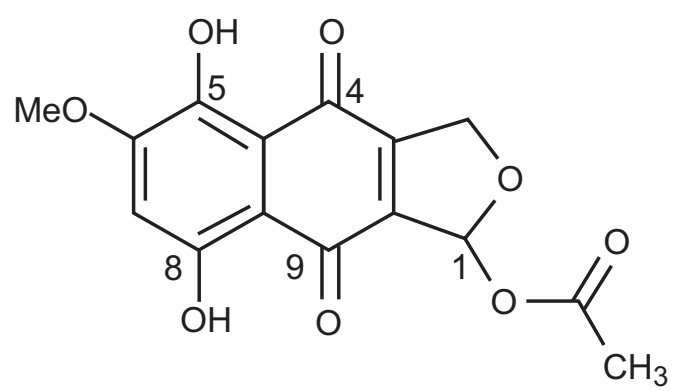

Fig. 4: 5,8-dihydroxy-6-methoxy-4,9-dioxo-1,3,4,9-tetrahydronaphtho l[2,3-c]furan-1-yl acetate (2).

The different solvent soluble fractions of the chloroform extract such as petroleum ether soluble fraction, ethyl acetate soluble fraction, methanol soluble fraction and isolated compounds were tested for antibacterial (Table-1) and antifungal (Table-2) activity against a number of Gram positive and Gram negative bacteria as well as some fungi. Standard disc ( $30 \mu \mathrm{g} / \mathrm{disc})$ of ciprofloxacin (CPFX) was used as positive control.

From this experiment, it was found that the Gram positive bacteria tested exhibited sensitivity to petroleum ether soluble fraction except Bacillus subtilis and Gram negative bacteria tested showed sensitivity except Shigella flexnari type-1 and Klebsiella $s p$. (Table 1). Among the Gram positive bacteria (Table 1), all test organisms showed considerable sensitivity to ethyl acetate soluble fraction except Bacillus cereus and Bacillus subtilis. The Gram negative bacteria also showed sensitivity except Vibrio minicus, Shigella boydii, Shigella flexnari type-1, Escherchia coli and Klebsiella $s p$. The methanol extract did not show any sensitivity against any bacteria tested.

Among the purified compounds SA-3(1) was not sensitive to Bacillus polymyx. Staphylococcus aureus, S. flexnari type-1 and Klebsiella $s p$. All other Gram positive bacteria were found sensitive to SA-3(1). In the case of compound SA-5(2), all Gram positive bacteria were found sensitive except Bacillus subtilis and Staphylococcus aureus. But Gram negative bacteria such as Vibrio cholera and Klebsiella sp. did not show any sensitivity to both SA-3 and SA-5. The maximum zone of inhibition in the antibacterial investigation was produced by chloroform extract of $S$. apetala against Pseudomonas sp.

The petroleum ether soluble fraction, ethyl acetate soluble fraction and methanol soluble fraction and purified compounds were investigated for antifungal activity (Table -2). Standard of Grisofulvin (GSF) was used as positive control.

Both fractions and compounds showed some sensitivity against Candida albicans, Aspergillus niger and Saccharromyces cerevisae except methanol soluble fraction.

Bioactive compounds are almost always toxic at higher concentration. In vivo lethality in an insect larvae can be used as a marker for screening and fractionation in the discovery of new bioactive natural products as an antitumor agent. In this bioassay, the ethyl acetate soluble fraction of $S$. apetala showed a significant cytotoxic activity in the brine shrimp lethality bioassay. 
Rahman et. al.

Table 1. Antibacterial activity of the extracts and compounds of S. apetala

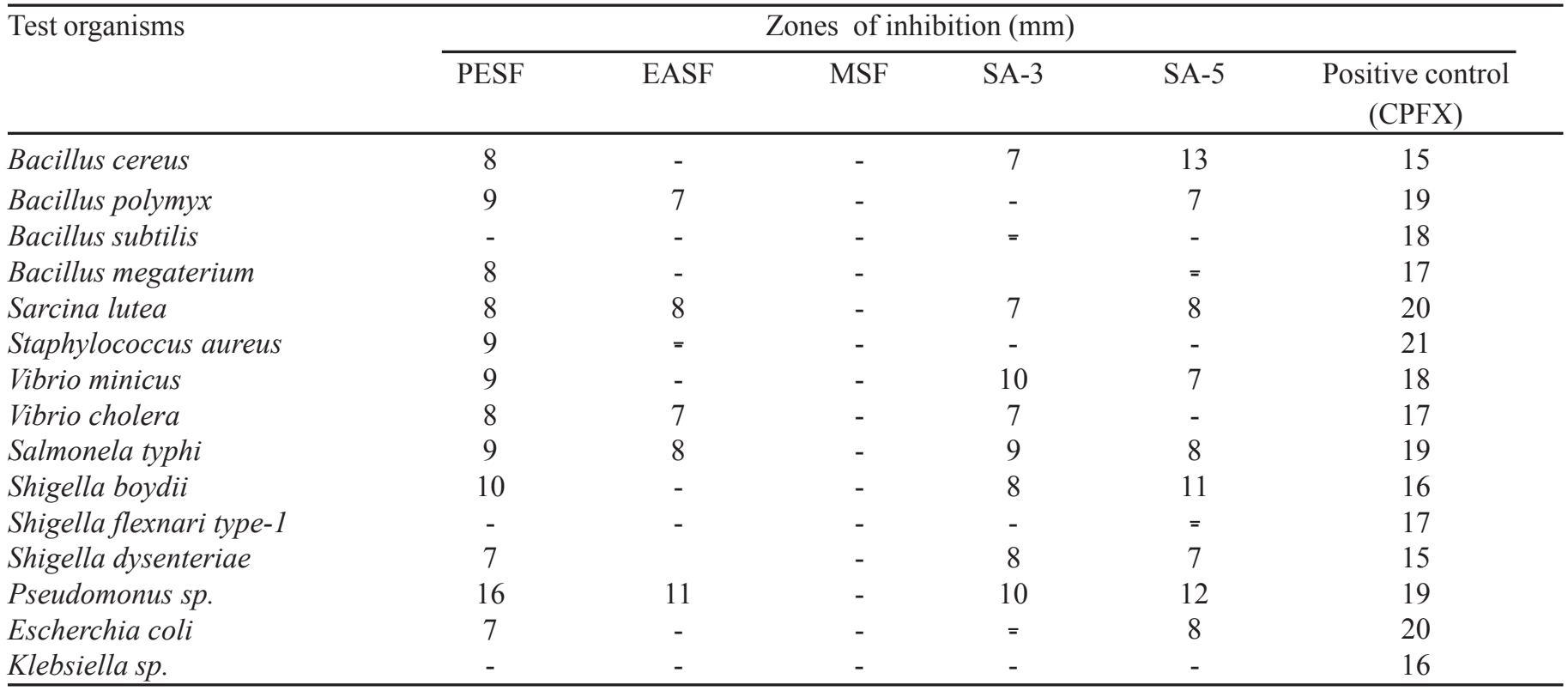

Table 2. Antifungal activity of the extracts and compounds of S. apetala

\begin{tabular}{lcccccc}
\hline Test organisms & \multicolumn{5}{c}{ Zones of inhibition (mm) } \\
\cline { 2 - 7 } & PESF & EASF & MSF & SA-3 & SA-5 & Positive control (GSF) \\
Candida albicans & 8 & $=$ & - & 7 & 9 & 15 \\
Aspergillus niger & 9 & 7 & - & 8 & 7 & 19 \\
Saccharromyces cerevisae & 7 & $=$ & - & $=$ & 8 & 18 \\
\hline
\end{tabular}

The sample showed different mortality rate at different concentrations. The mortality rate of brine shrimp was found to be increased with the increase of the concentration for each sample. The percent of mortality of the brine shrimp nauplii were calculated for every concentration for each sample. A plot of log of concentration of the sample versus percent mortality was showed an approximate linear correlation between them. From the graph (Figure-5), Log C value was found (Table-3). Therefore $\mathrm{LC}_{50}$ values of plant extract were calculated by probit analysis and $\mathrm{LC}_{50}$ was found to be $7.72 \mu \mathrm{g} / \mathrm{ml}$. It is evident from the result (Table-3) that the extract was toxic to the brine shrimp.

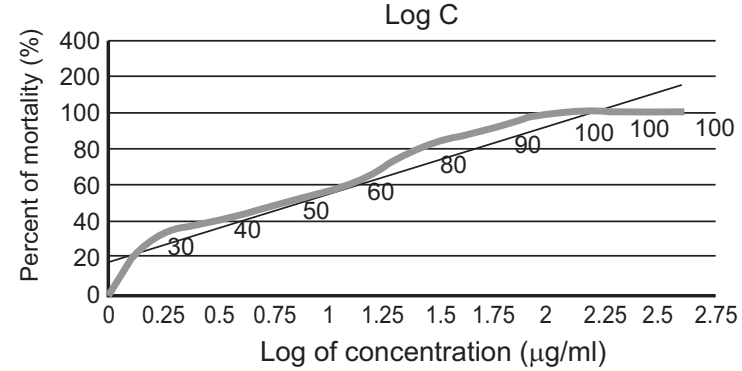

Fig. 5. Effects of chloroform extracts of $S$. apetala on brine shrimp.

Table-3. Determination of $L C_{50}$ of brine shrimp lethality bioassay for the plant extract of $S$. apetala

\begin{tabular}{lcccc}
\hline $\begin{array}{c}\text { Sample no. } \\
\text { Conc. of plant extract } \\
(\mu \mathrm{g} / \mathrm{ml})\end{array}$ & Log C & $\begin{array}{c}\text { Percent of mortality } \\
\text { of brine shrimp }\end{array}$ & Mean \\
\hline 1 & 400.00 & 2.602 & 100 & 100.00 \\
2 & 200.00 & 2.301 & 100 & 93.33 \\
3 & 100.00 & 2.000 & 100 & 90.00 \\
4 & 50.00 & 1.699 & 90 & 83.33 \\
5 & 25.00 & 1.398 & 80 & 70.00 \\
6 & 12.50 & 1.097 & 60 & 53.33 \\
7 & 6.25 & 0.796 & 50 & 40.00 \\
8 & 3.13 & 0.495 & 40 & 23.33 \\
9 & 1.54 & 0.194 & 30 & 20.00 \\
10 & 00.00 & - & 00 & 00.00 \\
\hline
\end{tabular}


The ascorbic acid used as standard which showed $\mathrm{IC}_{50}$ of $10.92 \mu \mathrm{g} / \mathrm{ml}$. The $\mathrm{IC}_{50}$ of methanol, petroleum ether and ethyl acetate soluble fraction of $S$. apetala were evaluated $18.00 \mu \mathrm{g} /$ $\mathrm{ml}$ (Figure-4), $10.50 \mu \mathrm{g} / \mathrm{ml}, 9.53 \mu \mathrm{g} / \mathrm{ml}$ respectively(table-4). By comparing the results with ascorbic acid, methanol, petroleum ether and ethyl acetate soluble fraction of $S$. apetala promising IC value.

Table 4. Antioxidant scavenging activity of $S$. apetala

\begin{tabular}{lcccc}
\hline Test sample & $\mathrm{IC}_{50}(\mu \mathrm{g} / \mathrm{ml})$ & Regression line & $\mathrm{R} 2$ & Activity \\
\hline Ascorbic acid & 10.92 & $\mathrm{Y}=25.74+31.07$ & 0.950 & Standard \\
PESF & 10.50 & $\mathrm{Y}=28.64+20.25$ & 0.988 & Moderate \\
EASF & 9.53 & $\mathrm{Y}=27.99+22.59$ & 0.996 & Higher \\
MSF & 18.00 & $\mathrm{Y}=21.63+37.36$ & 0.985 & Highest \\
\hline
\end{tabular}

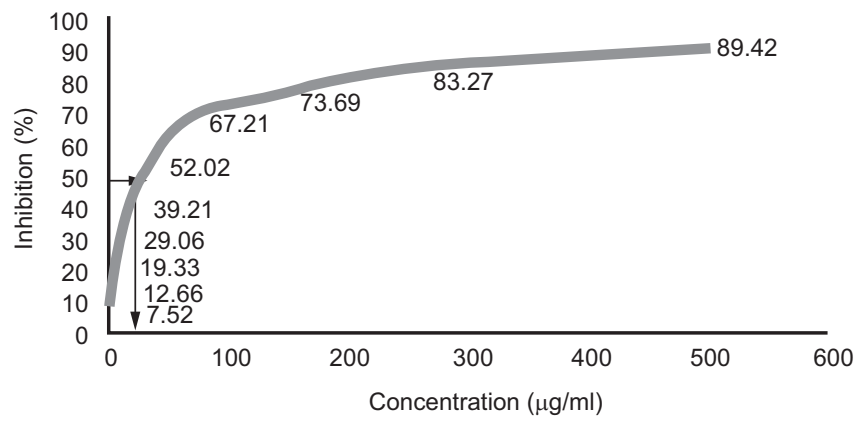

Fig. 6. $I C_{50}$ value of Methanol soluble fraction of the Chloroform extract.

From this investigation, it can be concluded that the plant has potential role in scavenging free radicals due to antioxidant activity.

\section{Conclusion}

The chloroform extract of the plant stem bark of Sonneratia apetala was investigated for the isolation and characterization of antimicrobial compounds and assay of biological activities of crude chloroform fractions and different partitionate like petroleum ether soluble fraction, ethyl acetate soluble fraction, methanol soluble fraction and aqueous soluble fraction. Successive chromatographic separation and purification yielded a total of two compounds which were identified and characterized as Taraxerone and 8-dihydroxy-6-methoxy-4,9dioxo-1,3,4,9-tetrahydronaphthol[2,3-c]furan-1-yl acetate by extensive proton NMR spectrum ( ${ }^{1} \mathrm{H}-\mathrm{NMR}$ specturm). Test materials of $S$. apetala were subjected to several biological screenings such as antimicrobial, brine shrimp lethality, antioxidant and cytotoxic activities. Biological activities showed by different partitionate were statistically evaluated. Here the antimicrobial sensitivity, brine shrimp lethality and antioxidant activities of the plant extracts showed promising results. Therefore, considering the potential biological activity, the plant materials can further be studied extensively to find out their unexplored efficacy and to rationalize their uses as traditional medicines. Further analysis and experiment can help to develop new anti-bacterial and antifungal drugs which might show fewer side effects.

\section{Acknowledgements}

We do express our thanks and gratitude to 'Institute of Nutrition and Food Sciences (INFS), University of Dhaka, Bangladesh' for providing the microbial strains for our research work.

\section{References}

1. Edward A. 2001. Pathogenesis Justiciaadhatoda (ed) New, Old and Forgotten remedies. pp 210-220.

2. Shinwari MI and M.A.Khan. 1998. Indigenous use of medicinal trees and shrubs of Margalla Hills National Park,Islamabad. Pak J Forest. 48 (1-4): 63-90.

3. Ayensu ES and DeFilipps RA. 1978. Book.Endangered and threatened plants of the United States. Washington, DC: Smithsonian Institution. pp 403-410.

4. Verpoorte R. 2000.Pharmacognosy in the new millennium: lead finding and biotechnology. J Pharm Pharmacol 52: 253-262.

5. Blatt, C.T.T., Salatino, A., Salatino, M.L.F., del Pero Martinez, M.A. and Cavalcanti, T.B. (1994). Flavonoids of Diplusodon(Lythraceae). Biochem Syst Ecol. 22: 101-107.

6. Santos DYAC, Salatino MLF and Salatino A. 1995. Flavonoids of species of Cuphea (Lythraceae) from Brazil. Biochem Syst Ecol. 23: 99-103.

7. Wolf RB, Graham SA and Kleiman R. 1983. Fatty acid composition of Cupheaseed oils. J Am Oil Chem Soc. 60: 103-104.

8. Santos DYAC, Salatino MLF and Salatino A. 2000. Flavonoids of Lafoensia(Lythraceae). Biochem Syst Ecol. 28: 487-488.

9. Graham SA and Kleiman R 1987. Seed lipids of the Lythraceae. Biochem Syst Ecol. 15: 433-439.

10. Parachayasittikul et al. 2010. Synthesis, Cytotoxic and Antimalarial Activities of Benzoyl Thiosemicarbazone Analogs of Isoquinoline and Related Compounds. Molecules 15(2): 988-996

11. Banes AW, Kinby WMM, Serris, JC and Wrch M, 1966. Antibiotic susceptibility testing by a standardized single disc method. American $J$ Clin Patho. 45: 493-496.

12. Meyer BN, Ferrigni NR, Putnam JE, Jacobsen LB, Nichols DE, and McLaughlin JL. 1982. A convenient general bioassay for active of plant constituents. Planta Med. 45(5): 31-34.

13. Masleinova R, Muschile J, Bernatoneine J, Mayiene D, Savichas A, Chalupura Z, and Dvorachova K, 2008. Antioxidant activity ogtinturey prepared from hawthorn fruits and motherwort herb. Cis. Slov, Farm. 57: 35-3. 